\title{
Tirésias: um modelo para acessibilidade ubíqua orientado à deficiência visual
}

\author{
Roberto Almeida Falk1 \\ João Elison da Rosa Tavares² \\ Jorge Luis Victória Barbosa ${ }^{3}$
}

\begin{abstract}
Resumo: Observa-se hoje um crescimento do número de dispositivos móveis disponíveis no mercado. Esses aparelhos estão cada vez mais ao alcance da população, seja pelo valor, cada vez mais acessível, seja pela facilidade de uso. Apesar disso, os sistemas operacionais desses dispositivos não estão preparados para atender pessoas com determinados tipos de deficiência, principalmente quando se trata de problemas visuais. $\mathrm{O}$ presente trabalho tem por objetivo propor um modelo de acessibilidade para dispositivos móveis, orientado ao suporte de pessoas que possuam algum nível de deficiência visual. Também são descritos cenários onde o modelo pode ser aplicado e o protótipo que foi desenvolvido para validá-los. Por fim, são apresentados os resultados obtidos após a execução dos cenários propostos.
\end{abstract}

Palavras-chave: Acessibilidade. Acessibilidade ubíqua. Computação Ubíqua.

\begin{abstract}
There are now a growing number of mobile devices on the market. These devices are increasingly more accessible to the population, because they are getting cheaper and also for being user friendly. Nevertheless, the operational system of these devices are not prepared to be used by people with certain types of disabilities, especially when it comes to visual problems. The aim of this work is to propose a model of accessibility for mobile devices to support people who have some level (full or partial) of visual impairment. In addition, the paper describes scenarios where the model could be applied, and the prototype that was developed to validate them.
\end{abstract}

Keywords: Accessibility. Ubiquitous accessibility. Ubiquitous computing.

\section{Introdução}

Há aproximadamente vinte anos, Mark Weiser introduziu o conceito de computação ubíqua [1], prevendo um mundo onde dispositivos computacionais estariam presentes em objetos, ambientes e nos próprios seres humanos, interagindo naturalmente com os usuários sem que fossem percebidos. Dez anos após, Satyanarayanan reforçou o conceito através de um artigo considerado clássico [2].

Nos últimos anos a evolução da tecnologia vem viabilizando a computação ubíqua, pois os equipamentos móveis estão cada vez menores e mais poderosos. Além disso, o advento das tecnologias de comunicação sem fio permitiu aos equipamentos acessarem serviços em qualquer lugar e a qualquer momento. Adicionalmente, a

\footnotetext{
${ }^{1}$ Programa de Pós-graduação em Computação Aplicada - UNISINOS

\{roberto.falk@gmail.com\}

${ }^{2}$ Programa de Pós-graduação em Computação Aplicada - UNISINOS \{joaotavaresti@gmail.com\}

${ }^{3}$ Programa de Pós-graduação em Computação Aplicada - UNISINOS \{jbarbosa@unisinos.br\}

http://dx.doi.org/10.5335/rbca.2013.2666
} 
crescente adoção de sistemas de localização [3,4] vem estimulando os serviços baseados em localização [5, 6] e os sistemas sensíveis ao contexto [7, 8].

Essa realidade tecnológica vem gerando novas oportunidades para diversas áreas, tais como Educação [9], Comércio [10] e Entretenimento [11]. Por sua vez, o presente artigo explora essas oportunidades tecnológicas na área de Acessibilidade.

Dados do último censo realizado no Brasil indicam a existência de 45,6 milhões de pessoas com deficiência (PCD), dentre as quais 35,7 milhões, ou seja, 78,2\% do total, são portadoras de deficiência visual (PCDV) [12]. Diante desses números, percebe-se a importância do investimento em tecnologias assistivas que suportem as necessidades dessa parcela da população.

Tecnologias assistivas são recursos e serviços tecnológicos que buscam facilitar as atividades diárias das PCD, aumentando sua capacidade, autonomia e independência [13]. A área de pesquisa dedicada à aplicação da computação ubíqua como tecnologia assistiva é denominada acessibilidade ubíqua (u-accessibility) [14].

Este artigo propõe um modelo para acessibilidade ubíqua, orientado à deficiência visual, denominado Tirésias $^{4}$. O Tirésias é baseado no modelo Hefestos ${ }^{5}$ [15]. O Hefestos enfoca diversos padrões de acessibilidade [13], não sendo orientado a um tipo específico de deficiência. O Tirésias pode ser compreendido como uma especialização do Hefestos para PCDV.

Sabe-se que um ponto crucial para concretização da acessibilidade consiste no projeto de interfaces especializadas [16, 17]. O projeto de interfaces acessíveis e adaptáveis é crítica para usuários com deficiência. $\mathrm{O}$ Tirésias possui como principal contribuição a integração de diferentes tecnologias móveis, visando uma interface amigável para suportar acessibilidade as PCDV.

O artigo está organizado como segue: a seção 2 apresenta a arquitetura de componentes do Tirésias, destacando sua integração com o Hefestos. A seção 3 discute aspectos de implementação e a seção 4 aspectos de avaliação. A avaliação é baseada em dois cenários envolvendo testes com o protótipo. A seção 5 destaca as contribuições do Tirésias através de uma discussão de trabalhos relacionados, e, por fim, na seção 6, são apresentadas as considerações finais.

\section{Modelo Tirésias}

O modelo Tirésias é composto por três módulos (saída, entrada e configuração) e um agente assistente pessoal (AAP). O AAP do Tirésias é uma especialização do assistente pessoal proposto pelo Hefestos [15], focado na acessibilidade de PCDV. Através do AAP, o Tirésias acessa o Hefestos, principalmente, para obtenção de perfis de usuários e recursos disponíveis nos contextos para suporte à acessibilidade. Ambos os tipos de informação para as PCDV devem ser incluídos através do Hefestos, o qual gerencia informações de diferentes padrões de acessibilidade [13]. O Tirésias gerencia a interface com as PCDV, acessando o Hefestos para obtenção das informações necessárias à acessibilidade. A Figura 1 mostra a arquitetura do Tirésias.

A Figura 1 mostra ainda que o Tirésias propõe a inclusão de um novo módulo na arquitetura do Hefestos. O módulo integrador atua como interface entre o Hefestos e o UniWay. O UniWay [18] é um sistema que usa o algoritmo de Dijkstra [19] para cálculo do menor caminho entre duas coordenadas geográficas mapeadas através de grafos em uma determinada região. Através dessa integração, o Hefestos disponibiliza caminhos a serem percorridos para alcançar determinado destino.

Os módulos do Tirésias basearam suas funcionalidades nos seguintes princípios estabelecidos de acessibilidade de PCDV [20]: (1) independência nas suas atividades diárias, sem necessidade de assistência ou acompanhamento de outras pessoas, sejam elas com ou sem deficiência visual; (2) o uso das funcionalidades não deve ser imposto, ou seja, as PCDV devem ter a liberdade de escolha das funcionalidades que mais se adequam às suas necessidades; (3) produtos específicos para PCDV tendem a ser mais caros e de difícil acesso e manutenção, sendo assim, o Tirésias suporta funcionalidades que podem ser usadas através de dispositivos comumente disponíveis no mercado, facilitando, assim, sua adoção. As próximas subseções descrevem os módulos do Tirésias.

\footnotetext{
${ }^{4}$ Profeta na mitologia grega portador de deficiência visual, mas com a capacidade de previsão do futuro.

${ }^{5}$ Deus da mitologia grega portador de deficiência física, o qual habilidosamente construía máquinas para superação de sua deficiência.
} 


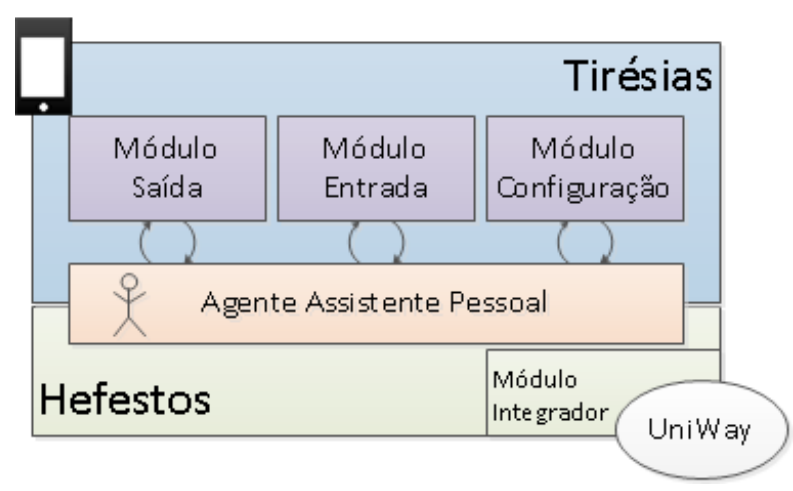

Figura 1: Arquitetura do modelo Tirésias

\subsection{Módulo de saída}

O módulo de saída disponibiliza informações oriundas do Hefestos as PCDV. Existem dois tipos de informações: (1) Tipo 1 - indicação de recursos de acessibilidade próximos ao usuário; (2) Tipo 2 - um caminho para um determinado destino escolhido pelo usuário. Ambas as informações são disponibilizadas através de dois recursos de interface discutidos nas próximas subseções: leitura de tela e alertas vibratórios.

\subsubsection{Leitura de tela}

A leitura de tela é um dos mais conhecidos recursos de acessibilidade para PCDV, sendo atualmente suportado pela maioria dos smartphones. Esse recurso deve ser utilizado com moderação, pois pode reduzir o nível de consciência situacional do usuário [21,22], ou seja, o nível de consciência dos acontecimentos ao seu redor. O problema é reduzido com a utilização de um fone em apenas um dos ouvidos. Outra opção é a utilização das caixas de som embutidas no smartphone, preservando a consciência situacional, ainda que a qualidade sonora possa ser prejudicada devido à má qualidade dos alto-falantes. Além disso, essa opção não pode ser utilizada em todas as situações devido a problemas de privacidade [21].

A disponibilização de recursos (informação do tipo 1) envolve a leitura do nome, da descrição e da distância de cada recurso. Os recursos são lidos de forma ordenada de acordo com a distância, ou seja, o recurso mais perto é lido inicialmente, seguido pelos mais distantes. Na medida em que o usuário se movimenta, ocorre uma atualização das informações relativas aos recursos. Novos recursos são lidos na medida em que são recebidos, enquanto que os recursos que já foram lidos são apenas atualizados na tela do aparelho. A qualquer momento o usuário pode solicitar ao sistema que releia itens da lista de recursos através da navegação na tela. A navegação no sistema e o controle de periodicidade de atualização podem ser configurados, conforme discutido na subseção 2.3 .

A disponibilização de caminhos (informação do tipo 2) segue a mesma lógica de leitura de tela, considerando o nome, a descrição e a distância, mas diferentemente dos recursos, os quais são disponibilizados todos ao mesmo tempo respeitando as distâncias, para os caminhos apenas o destino parcial mais próximo é disponibilizado. Após o usuário atingir esse destino parcial, o próximo é lido. Dessa forma cada trecho é disponibilizado em sequência, simplificando o deslocamento das PCDV.

\subsubsection{Alertas vibratórios}

Além da leitura de tela, um sistema de navegação baseado na analogia de ponteiros de relógio [23] pode ser usado para indicação de direções a serem seguidas pelas PCDV. No entanto, o entendimento da direção de ponteiros varia entre os usuários, dificultando a adoção dessa solução. Como alternativa, o Tirésias suporta alertas vibratórias para indicação da direção que deve ser seguida para atingir determinado recurso ou destino. Quando o usuário seleciona um recurso ou destino, a direção do mesmo será indicada com uma vibração, quando o usuário estiver com o dispositivo voltado para ela. A vibração é interrompida quando o usuário desvia o aparelho para qualquer outra direção. Essa funcionalidade é disponibilizada através da utilização da bússola eletrônica disponível nos smartphones. 


\subsection{Módulo de entrada}

No caso das PCDV a tela não pode ser usada como forma de retorno sobre a ação executada. Através da memorização, pessoas com experiência podem digitar com sucesso sem olhar para o dispositivo, mas apenas após anos de êxito, utilizando sempre o retorno da tela como guia [24].

Em relação à entrada de dados, os dispositivos atuais podem ser divididos em dois grupos, considerandose a existência ou não de teclado. Dispositivos com teclado normalmente apresentam um pequena marca na tecla ' 5 ', servindo de referência para o usuário. Essa informação é útil quando se deseja apenas digitar os números, mas quando se deseja digitar as letras, não há nenhuma informação quanto à disposição das mesmas no teclado numérico. Para tentar minimizar esse problema o leitor de tela pode ser utilizado, provendo retorno para o usuário à medida que ele vai digitando as letras, assim, cada letra digitada é repetida pelo sistema, a fim de possibilitar a verificação por parte do usuário sobre o que foi digitado está correto.

Outra abordagem se chama BloNo [25], que se trata de um sistema que divide o alfabeto em linhas e colunas, cada linha iniciando com uma das cinco vogais do alfabeto, uma vez que essas letras são mais fáceis de serem lembradas do que outras escolhidas ao acaso. O usuário então acessa o alfabeto navegando nas linhas e colunas, utilizando o teclado numérico como setas. Juntamente com o feedback retornado pelo leitor de tela, o sistema BloNo viabiliza o uso de teclados numéricos. Da mesma forma que dispositivos com teclados numéricos, aparelhos com teclado completo (teclado QWERTY) devem fazer uso do leitor de tela, a fim de prover retorno ao usuário do que está sendo digitado.

Dispositivos com tela sensível ao toque geram vários problemas de interação para as PCDV, pois dependem completamente da tela para fornecer retorno ao usuário [24]. A leitura da tela pode ser usada para amenizar essa limitação. Uma alternativa seria ainda dispor de uma lista de opções baseadas em números, onde para selecionar a opção desejada, o usuário necessita apenas tocar no número correspondente. Dessa forma, a interação com o sistema torna-se facilitada.

O Tirésias considera ambos os tipos de dispositivos. Nos dispositivos com tela sensível ao toque, a navegação na lista de recursos ocorre através de gestos. O movimento do dedo na tela do dispositivo permite a leitura dos recursos na lista, ou seja, um movimento para cima permitirá a leitura de um recurso anterior na lista e um movimento para baixo avançará na lista. Além disso, o clique simples na tela é desconsiderado, pois o usuário normalmente não tem a exata noção de onde está clicando. A seleção de um recurso específico após a sua leitura envolve um clique duplo em qualquer parte da tela. Após selecionar um recurso, para voltar à lista completa, o usuário deve utilizar o clique triplo, também em qualquer parte da tela. A navegação para modelos com teclado segue a lógica de setas, conforme descrito anteriormente. A seleção de um recurso é realizada com a tecla ' 5 ' e o retorno usa a tecla ' 1 '.

\subsection{Módulo de configuração}

Considerando-se PCDV, a configuração das funcionalidades de um sistema assistivo assume relevância significativa. Por exemplo, uma leitura de tela excessivamente rápida pode dificultar o uso do leitor. No Tirésias, o módulo de configuração permite o controle de cada uma das funções disponíveis. Dessa forma, o Tirésias pode ser customizado aos diferentes usuários.

A possível redução do nível de consciência situacional ocasionada pela leitura de tela [21,22] pode ser mitigada através do controle da frequência e do volume que a informação será lida [26]. No Tirésias existem duas configurações para o leitor de tela. A primeira controla o volume de leitura e a segunda o número de recursos que devem ser informados ao mesmo tempo. Assim, o tempo necessário para ouvir as informações será diretamente proporcional ao número de recursos recebidos em um mesmo momento.

Um controle adicional refere-se ao nível de intrusão do AAP, pois muitas vezes o usuário não deseja ser alertado a todo o momento sobre recursos a sua volta. No Tirésias o usuário pode configurar se deseja ou não que o AAP o notifique sobre a mudança de recursos no ambiente. Se as notificações estão desativadas, o usuário não será alertado proativamente sobre recursos.

\subsection{Agente assistente pessoal}

A Figura 2 mostra a atuação do AAP através de um diagrama de ações usando a metodologia Prometheus [27]. O Hefestos foi representado através de um agente. A estrela representa a percepção suportada pelo agente. As flechas representam as ações que podem ser realizadas pelo agente, dependendo de uma percepção. Os envelopes representam as mensagens trocadas entre agentes. Os agentes são representados por um retângulo. 


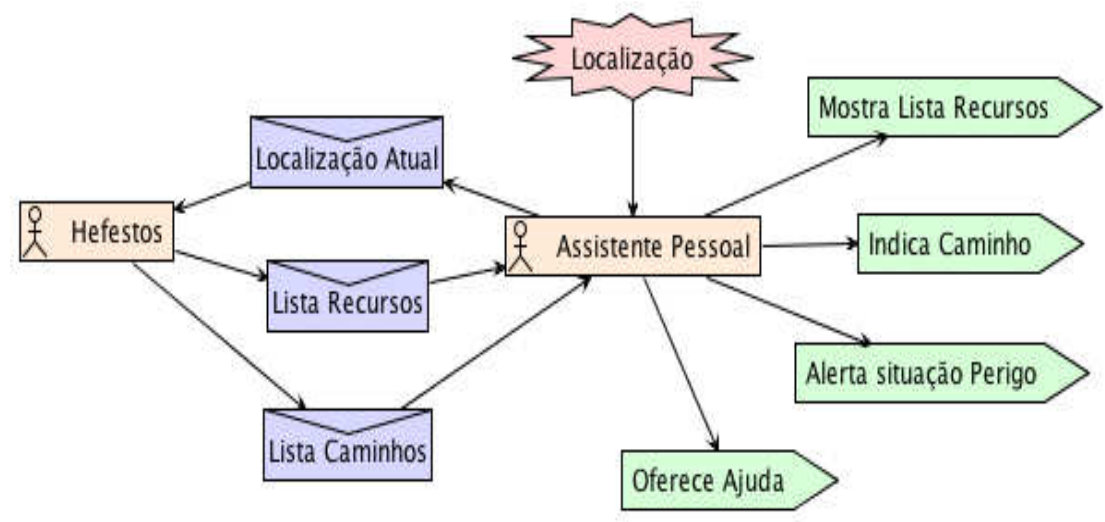

Figura 2: Modelagem do agente assistente pessoal (AAP)

Através da percepção suportada (localização), diferentes ações podem ser executadas, onde a movimentação ou não gera ações por parte do agente. Uma nova localização indica que o usuário está em movimento. Esse comportamento implica em uma necessidade de atualização dos recursos que estão sendo sugeridos (Mostra Lista de Recursos), ou do caminho que deve ser seguido para atingir um destino (Indica Caminho).

Além disso, o agente pode também alertar o usuário para possíveis perigos no caminho, por exemplo, uma escada (Alerta situação Perigo). Nesse sentido, o AAP considera a categoria de dificuldade do trecho a ser percorrido. As categorias são registradas na base de dados do UniWay. Quando o trecho possui uma categoria que indique uma maior dificuldade, o AAP emite alertas vibratórios moderados, informando o usuário da dificuldade eminente.

Uma mesma localização recebida durante um longo tempo pode indicar que o usuário encontra-se perdido, ou não tem certeza de qual caminho seguir. Baseado nessa percepção, o AAP oferece ajuda de forma proativa (Oferece Ajuda). Assim, o usuário poderá enviar uma solicitação de auxílio. O Tirésias identifica, via Hefestos, o usuário com perfil assistivo mais próximo (por exemplo, funcionários de segurança) e envia a este uma notificação solicitando auxílio e informando a localização do usuário solicitante.

Por sua vez, o usuário recebe uma notificação informando que a solicitação foi processada, contendo a distância que o usuário assistivo se encontra. Com base nessa informação, o usuário solicitante pode ter uma ideia do tempo que levará para ser atendido. Visto que o AAP não está conectado de forma contínua (online) com o servidor, torna-se importante que o usuário mantenha sua posição até que o usuário assistivo chegue, evitando assim possíveis desencontros.

A Figura 2 mostra ainda a principal relação entre o AAP e o Hefestos. O AAP envia sua localização (localização atual) e recebe como resposta a lista de recursos próximos (lista recursos). Ao selecionar um recurso, o usuário tem a opção de receber a indicação quanto à direção deste, utilizando os alertas vibratórios, ou de solicitar informações quanto ao caminho a ser percorrido para chegar ao recurso. No caso do caminho, o AAP recebe do Hefestos uma lista com os trechos a serem percorridos no caminho (lista caminhos).

\section{Protótipo tirésias}

Um protótipo do modelo Tirésias foi desenvolvido para iPhone utilizando a linguagem Objective-C, sendo denominado Tirésias App. O protótipo considerou recursos reais mapeados no campus da Universidade do Vale do Rio dos Sinos (Unisinos ${ }^{6}$ ). A Figura 3 mostra o mapa da área de abrangência do Tirésias App e a Tab. 1 apresenta a lista dos recursos mapeados.

As seguintes inclusões foram realizadas na base de dados do Hefestos: (1) inclusão de uma nova deficiência chamada "Deficiência Visual"; (2) inclusão de recursos orientados a PCDV (Tab. 1); (3) inclusão de novos usuários com o perfil de PCDV. Após essas inclusões, o Hefestos tornou-se capaz de inferir resultados para PCDV e, dessa forma, interagir com o Tirésias App.

\footnotetext{
${ }^{6}$ Homepage da Unisinos: http://www.unisinos.br
} 


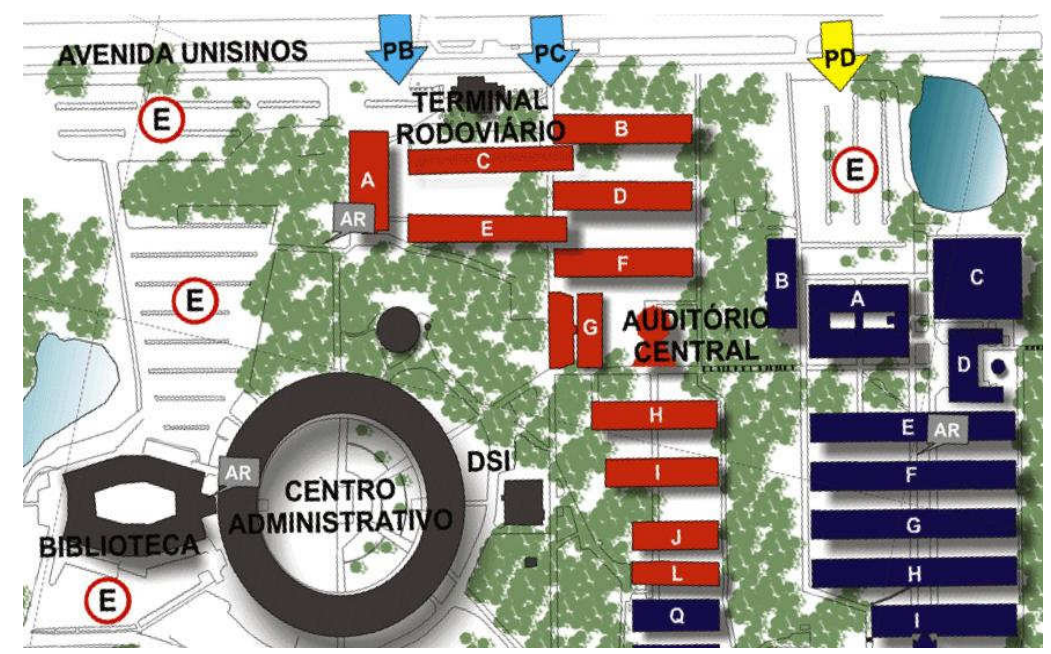

Figura 3: Mapa da área de abrangência do protótipo

Tabela 1. Recursos registrados no Hefestos para suporte ao Tirésias App

\begin{tabular}{|l|l|l|l|}
\hline \multicolumn{1}{|c|}{ Nome do Recurso } & Descrição do Recurso & \multicolumn{1}{c|}{ Latitude } & \multicolumn{1}{c|}{ Longitude } \\
\hline Portão 6 & Portão de entrada & -29.792005 & -51.153124 \\
\hline Centro 6A & Centro de Exatas & -29.793138 & -51.1528 \\
\hline Centro 6B & Centro de Exatas & -29.793005 & -51.152422 \\
\hline Banheiro Acessível & Banheiro & -29.793617 & -51.151939 \\
\hline Restaurante Happystation & Restaurante & -29.793291 & -51.151818 \\
\hline Livraria do Abílio & Livraria & -29.793259 & -51.151915 \\
\hline Auditório Central & Auditório & -29.793603 & -51.153582 \\
\hline Ambiente de Relacionamento & Relacionamento & -29.793743 & -51.151813 \\
\hline Biblioteca & Biblioteca & -29.794902 & -51.15611 \\
\hline Centro Administrativo & Centro Geral & -29.794725 & -51.15479 \\
\hline Banheiro Acessível & Banheiro & -29.795172 & -51.155176 \\
\hline Restaurante StationCoffee & Restaurante & -29.794381 & -51.155627 \\
\hline
\end{tabular}

A Figura 4a apresenta a tela inicial do protótipo. A opção pela "Lista de Recursos" conduz a tela de recursos (Figura 4b), na qual o usuário pode escolher um detalhamento (Fig. 4c).

No módulo de saída foram implementados o leitor de tela e os alertas vibratórios, utilizando as classes nativas disponibilizadas pelo Objective-C. No caso do leitor foram consideradas outras opções de código aberto (por exemplo, OpenEars [28]). No entanto, após uma avaliação baseada em testes concluiu-se que o leitor nativo da linguagem apresentava uma leitura mais qualificada de frases e palavras.

No módulo de entrada implementou-se a interpretação de gestos, permitindo a leitura dos itens da lista de recursos enquanto o usuário desliza o dedo na tela. Um item anterior pode ser relido a qualquer momento, aumentando a usabilidade do sistema.

O clique simples foi desconsiderado. A seleção de um item envolve um clique duplo em qualquer parte da tela. O retorno para opções anteriores envolve um clique triplo.

$\mathrm{Na}$ tela de detalhes do recurso (Fig. 4c) existe uma indicação da direção do recurso selecionado. A direção em graus é calculada pelo Hefestos e recebida pelo Tirésias juntamente com as informações do recurso. O Tirésias utiliza a bússola integrada no iPhone para indicar ao usuário a direção do recurso. Assim, quando o usuário estiver com o aparelho voltado para o recurso, alertas vibratórios são emitidos indicando a direção. 


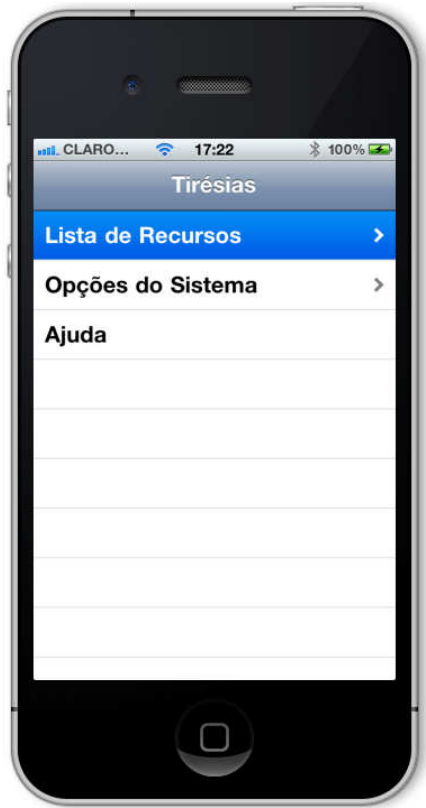

(a) Tela inicial

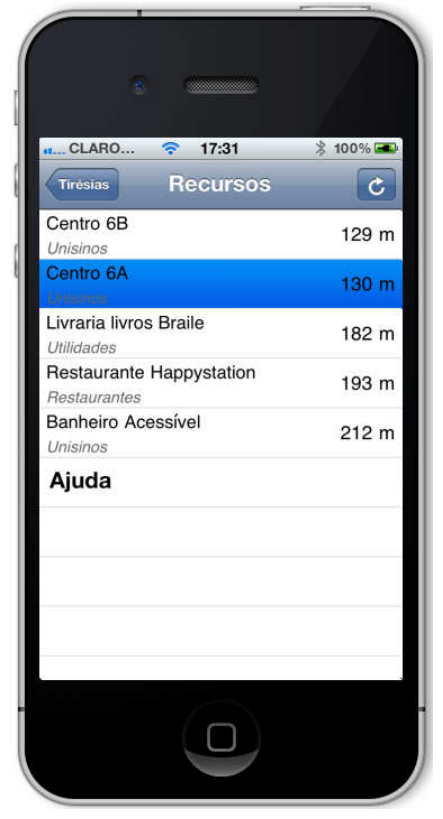

(b) Lista de recursos

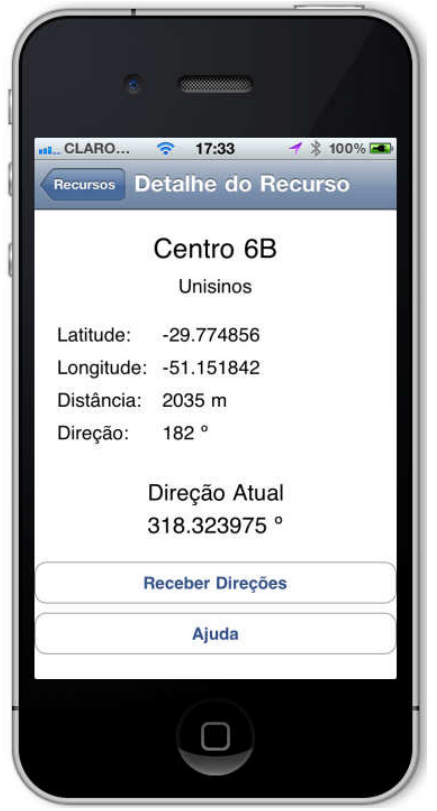

(c) Detalhes do recurso

Figura 4: Telas do Tirésias App

A tela de detalhes (Fig. 4c) permite ainda a seleção de duas ações, ou seja, "Receber direções" e "Ajuda". Através da primeira, o Tirésias recebe do Hefestos a lista de trechos a serem percorridos para atingir o recurso. A Figura 5 mostra a dinâmica para acesso ao caminho que leva ao auditório central da Unisinos.

A estratégia de leitura dos trechos que compõem um caminho difere da leitura da lista de recursos, pois apenas o trecho atual é lido. Após o usuário percorrer o trecho, o ponto é removido da lista e o próximo trecho é lido. Dessa forma, os trechos são percorridos sequencialmente, de forma ordenada e segura. A Figura 6a mostra uma imagem de satélite contendo os sete pontos do caminho exemplificado na Figura 5.

Os cruzamentos indicados pelos pontos 2, 3, 4, 5 e 6 não representam destinos, mas possíveis pontos de mudança no caminho. No exemplo, caso o usuário desejasse uma indicação para o prédio 6B (prédio à esquerda do ponto 3 na Figura 6a), a mudança no caminho seria indicada a partir do ponto 3 .

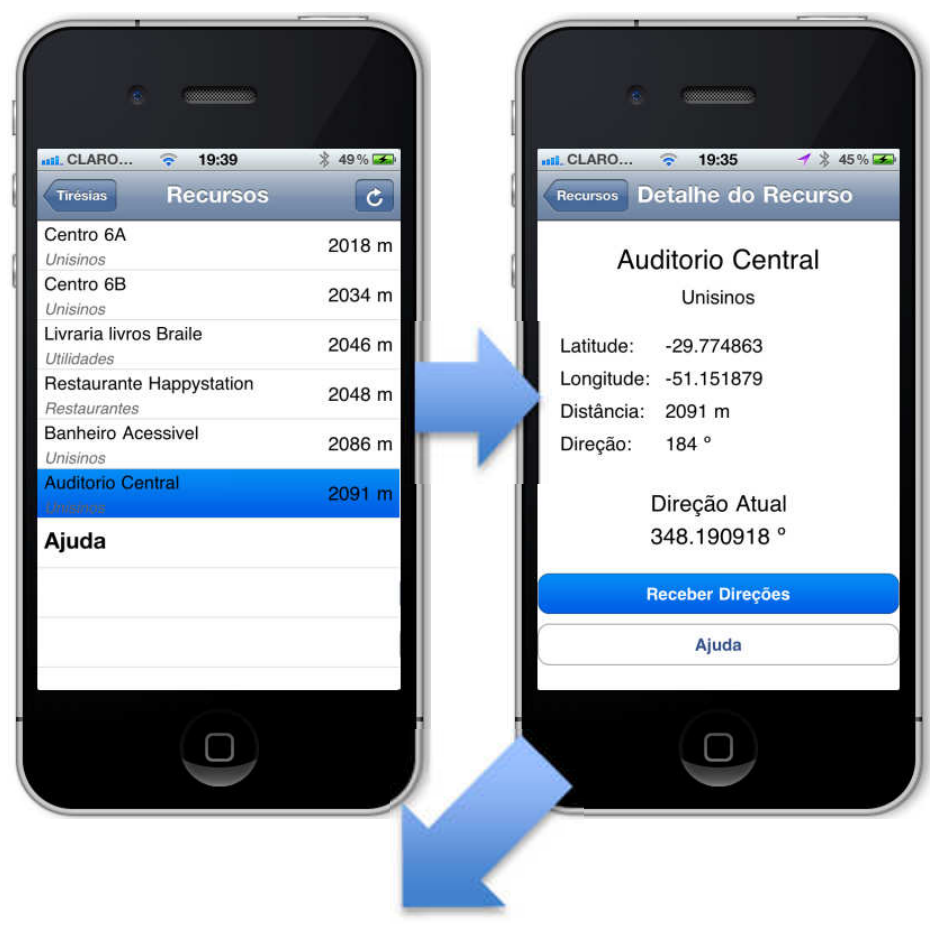




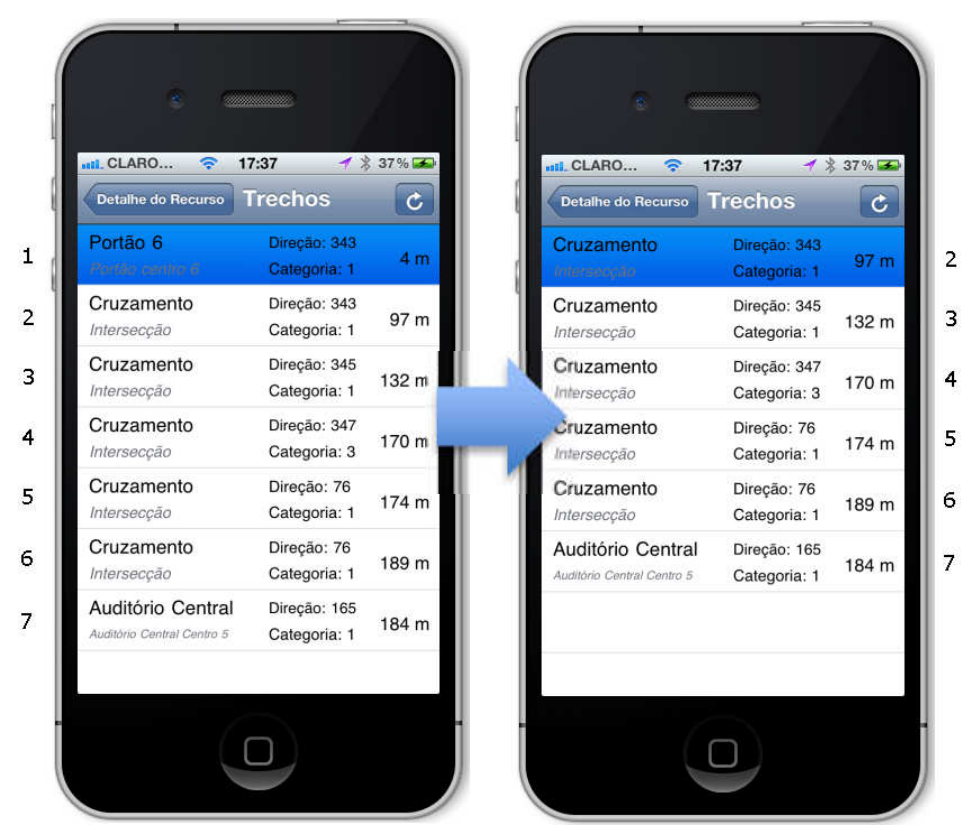

Figura 5: Exemplo de caminho disponibilizado pelo Tirésias

Adicionalmente, o usuário recebe indicações quanto à direção a ser percorrida através de alertas vibratórios guiados pela direção do dispositivo. Além disso, alertas também indicam a dificuldade do trecho a ser percorrido. O campo "categoria" (Fig. 5) indica o nível de dificuldade do trecho. Caso o valor do campo seja maior que dois, um alerta vibratório é emitido. Nas figuras 5 e 6a, pode ser visualizado o trecho de número 4, o qual foi sinalizado com a categoria três, indicando um aclive ou declive moderado (escada ligando dois centros da Unisinos).

Todas as telas disponibilizam o botão de ajuda, por meio do qual o usuário pode solicitar auxílio. No contexto da Unisinos, esse papel é cumprido pelos funcionários de segurança. A Figura 6 b exemplifica o uso do sistema de ajuda.

A implementação do Módulo de Configuração permite o ajuste de uma série de parâmetros do Tirésias App (Fig. 6c), tais como, o volume e a velocidade de leitura de tela, a frequência de comunicação com o Hefestos (por tempo ou por distância percorrida) e a quantidade máxima de recursos que serão apresentados ao mesmo tempo. 


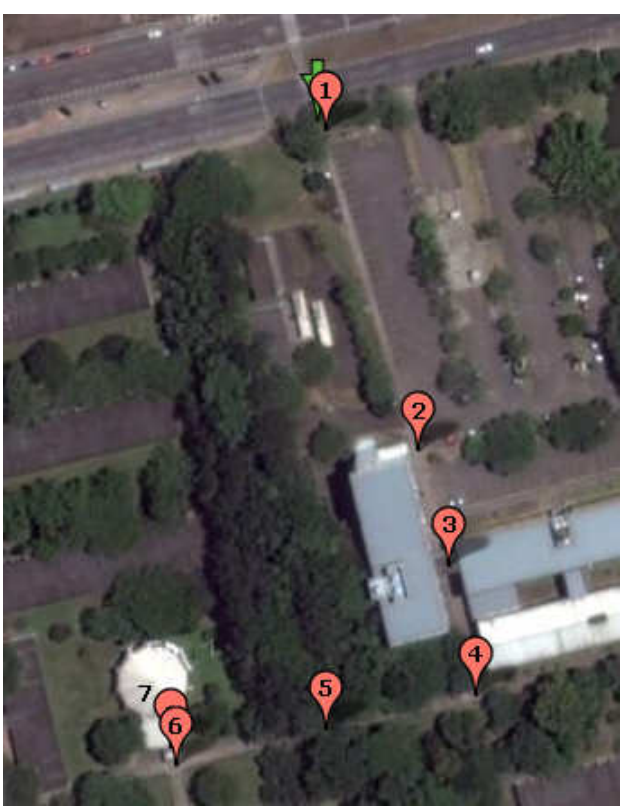

(a) Mapa com trechos

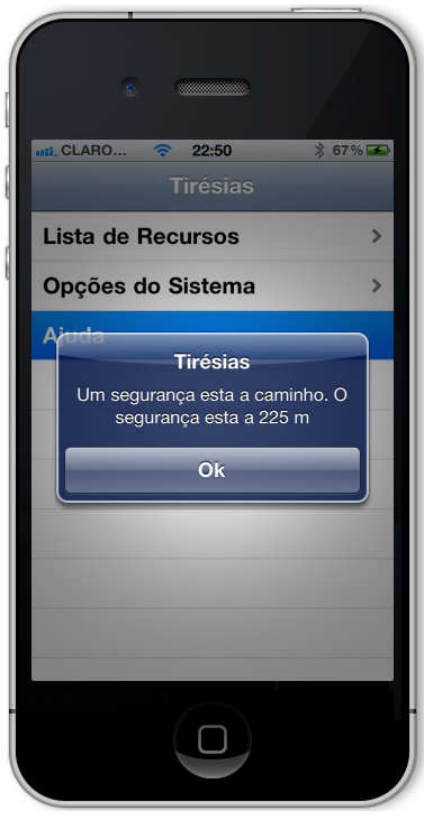

(b) Tela de ajuda

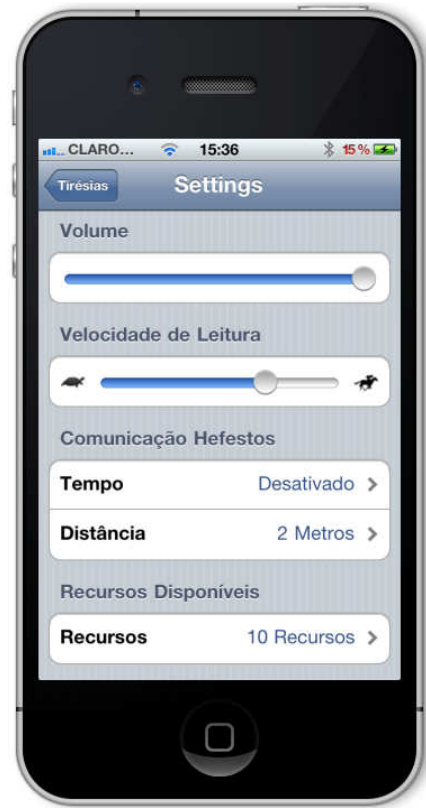

(c) Tela de configuração

Figura 6: Mapa com trechos e telas de ajuda e configuração

\section{Avaliação através de cenários}

A comunidade científica vem usando cenários para validação de sistemas sensíveis ao contexto (abordagem de Dey [29]), sistemas ubíquos (abordagem de Satyanarayanan [2]) e sistemas de acessibilidade ubíqua [15]. Seguindo essa estratégia foram criados dois cenários para avaliação do Tirésias, que foram executados por um usuário ${ }^{7}$ portando um iPhone 4 e deslocando-se no ambiente mostrado na Figura 3 . O cenário 1 mostra a chegada de um aluno deficiente visual à universidade e sua interação inicial com os recursos sugeridos pelo Tirésias App. No cenário 2 o aluno avança na sua interação com o ambiente, explorando recursos adicionais.

\subsection{Cenário 1}

"Roberto é um estudante da Universidade do Vale do Rio dos Sinos portador de deficiência visual. Ele está usando o Tirésias App no seu smartphone. Ao se aproximar do portão D para pedestres, próximo ao centro 6, Roberto recebe a lista de recursos de acessibilidade mais próximos. A lista é lida à medida que ele navega nos itens através de gestos na tela. Conforme ele caminha na calçada do estacionamento do centro 6, outros recursos são recebidos. Ao se aproximar do prédio A, Roberto decide receber indicações quanto à direção que se encontra o banheiro que foi sugerido como estando a poucos metros. Roberto então navega na lista até selecionar 'Banheiro Acessivel', e confirma a seleção através de um clique duplo na tela. Na tela de detalhes do recurso, Roberto aponta o dispositivo para frente a fim de verificar se ele está voltado para o lado correto a seguir. Visto que o aparelho não emitiu qualquer vibração, ele começa a rotacionar lentamente o equipamento, esperando que o mesmo indique a direção. Após alguns momentos o aparelho começa a vibrar, e Roberto então segue para o lado indicado, encontrando a porta do banheiro (Figuras 7 a e 7b). Após sair do banheiro, Roberto verifica o que mais há na lista de recursos que está sendo sugerida. Ele seleciona então o recurso 'Auditório Central', mas, considerando que Roberto não sabe como chegar no auditório, ele decide solicitar indicações de caminho. Para isso, após selecionar o recurso através do clique duplo, Roberto novamente navega nas opções da tela de detalhes até ouvir a opção 'Receber Direções'. Ele utiliza novamente o clique duplo para confirmar a opção selecionada. Após isso, o Tirésias inicia a leitura do primeiro trecho a ser seguido para alcançar o destino 'Auditório Central'. Em um determinado momento, o aparelho começa a emitir vibrações. Roberto sabe que as vibrações indicam que o próximo trecho apresenta uma dificuldade maior para ser superado. Por causa disso, ele decide solicitar ajuda a um funcionário que estiver nas proximidades. Roberto executa o clique triplo

${ }^{7} \mathrm{O}$ usuário não é portador de deficiência visual. Sendo assim, os testes avaliaram a funcionalidade do sistema e não sua usabilidade. 
para voltar à tela de detalhamento do recurso, e logo após, seleciona a opção 'Ajuda'. Roberto recebe então a informação de que um funcionário foi contatado com sucesso e que está a poucos metros de distância".

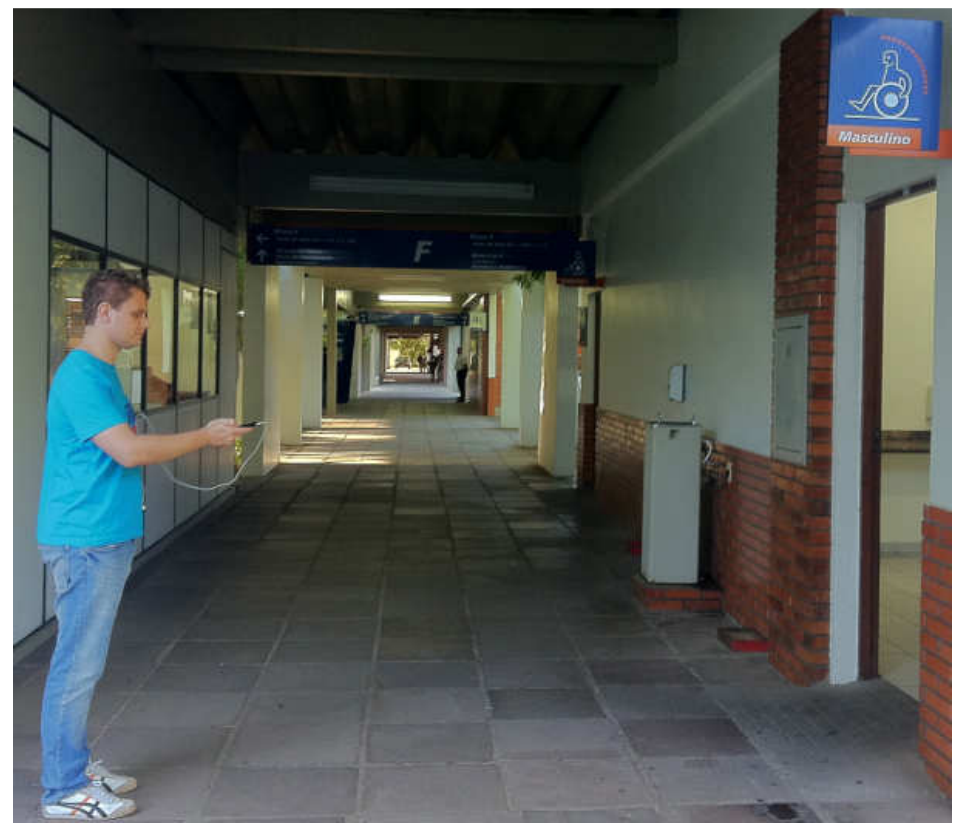

a) Teste dos alertas vibratório indicativos de direção

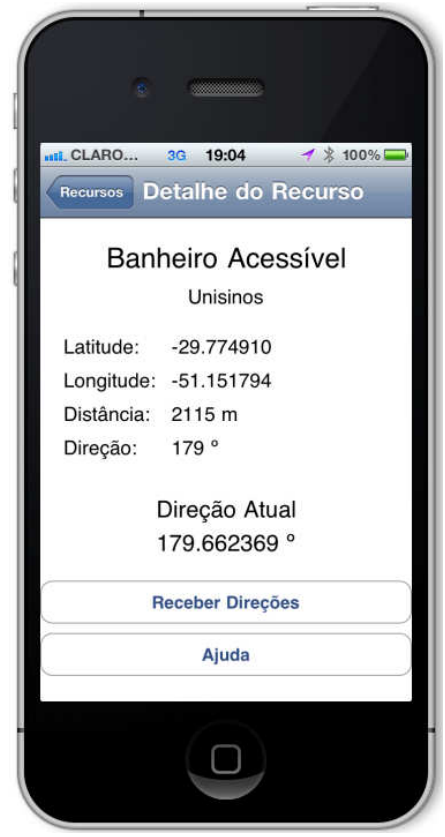

b) Captura de tela durante o teste dos alertas vibratórios

Figura 7: Execução do primeiro cenário

A Tabela 2 resume a dinâmica do cenário, destacando os atores e as ações.

Tabela 2. Dinâmica do primeiro cenário

\begin{tabular}{|l|l|}
\hline \multicolumn{1}{|c|}{ Ator } & \multicolumn{1}{c|}{ Ação } \\
\hline Usuário & Aproxima-se do portão D da universidade. \\
\hline Tirésias App & $\begin{array}{l}\text { Considerando a localização do usuário, o Tirésias se comunica com o Hefestos e recebe a lista de } \\
\text { recursos próximos. A lista então é disponibilizada para o usuário. }\end{array}$ \\
\hline Usuário & Navega na lista de recursos e caminha pela universidade. \\
\hline Tirésias App & $\begin{array}{l}\text { Ao detectar mudanças na localização, o Tirésias novamente se comunica com o Hefestos, recebendo a } \\
\text { lista de recursos. Os novos recursos são disponibilizados para o usuário. }\end{array}$ \\
\hline Usuário & Navega na lista de recursos e seleciona ‘Banheiro Assistivo’. \\
\hline Tirésias App & $\begin{array}{l}\text { Usando a bússola eletrônica do dispositivo, uma vibração é emitida quando o usuário está com o aparelho } \\
\text { voltado para a direção do recurso. }\end{array}$ \\
\hline Usuário & Caminha para a direção indicada até encontrar o banheiro. \\
\hline Usuário & Seleciona o recurso "Auditório Central”, e na tela de detalhes do recurso seleciona "Receber Direções". \\
\hline Tírésias App & $\begin{array}{l}\text { Envia ao Hefestos a localização do usuário e solicita um caminho a ser seguido. Após receber a lista de } \\
\text { trechos, inicia a leitura do primeiro trecho do caminho. }\end{array}$ \\
\hline Usuário & Segue as indicaç̃̃es referentes aos trechos lidos. \\
\hline Tirésias App & Começa a emitir vibrações, pois o valor do campo "Categoria” é maior que dois para o próximo trecho. \\
\hline Usuário & $\begin{array}{l}\text { Executa o clique triplo para cancelar a função de direcionamento e voltar à tela de detalhes do recurso. } \\
\text { Nessa tela o usuário seleciona a opção de "Ajuda". }\end{array}$ \\
\hline Tirésias App & $\begin{array}{l}\text { Envia ao Hefestos a localização do usuário e solicita ajuda. O Hefestos responde que encontrou um } \\
\text { funcionário bem como a distância do mesmo. Essa informação é lida ao usuário. }\end{array}$ \\
\hline
\end{tabular}




\subsection{Cenário 2}

“Após sair do auditório central Roberto decide ir ao centro administrativo. Para isso ele navega na lista de recursos que está sendo apresentada e seleciona o recurso 'Centro Administrativo'. Na tela de detalhes do recurso ele navega nas opções até ouvir a opção 'Receber direções', confirmando a seleção através do clique duplo. Logo após, o Tirésias inicia a leitura do primeiro trecho do caminho. Roberto segue os passos indicados pelo aparelho sem dificuldades, pois o caminho é plano e sem desvios, chegando ao destino (Figuras 8a e 8b). Ao fim do atendimento no centro administrativo, Roberto decide passar na biblioteca antes de ir para casa. Novamente ele navega nas opções de recursos até ouvir a leitura do recurso 'Biblioteca', selecionando o mesmo com o clique duplo. Ele navega nas opções e seleciona 'Receber indicações'. O Tirésias inicia a leitura dos trechos a serem percorridos. Ao chegar à porta da biblioteca (Fig. 8c), Roberto decide solicitar ajuda a um funcionário, pois sabe que a aplicação não funciona de forma precisa dentro de locais fechados, em função do uso de GPS. Assim, Roberto utiliza o clique triplo para voltar à tela de detalhes do recurso, e após navega até a opção 'Ajuda'. Logo após o Tirésias informa que um funcionário está a caminho, informando também a sua distância."

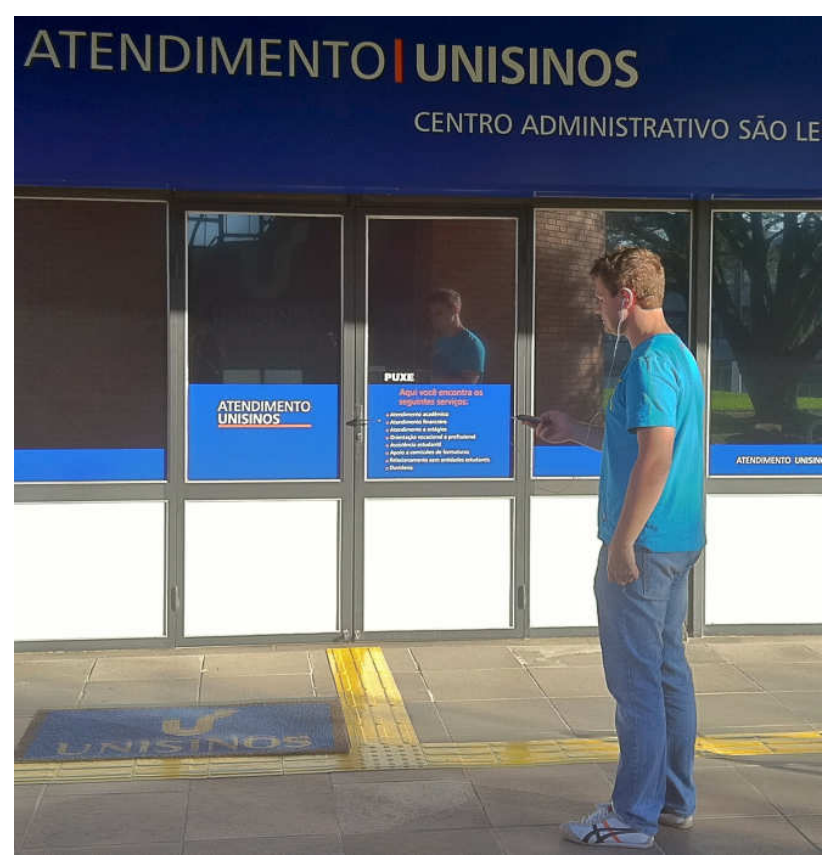

a) Teste da indicação de caminhos

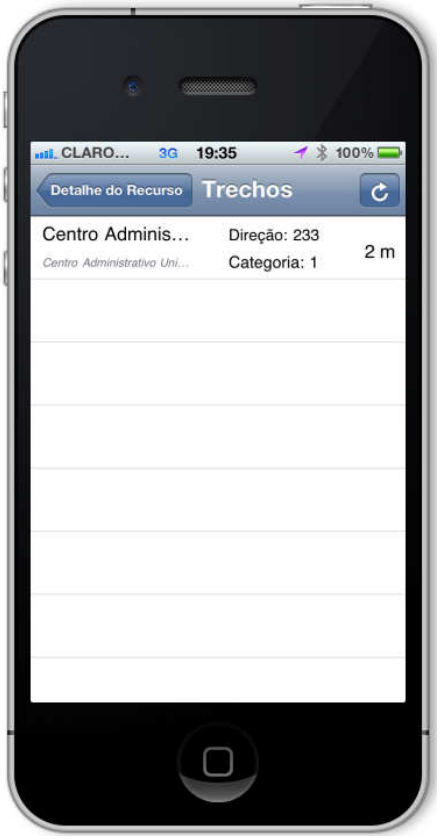

b) Captura de tela durante o teste de indicação de caminho 


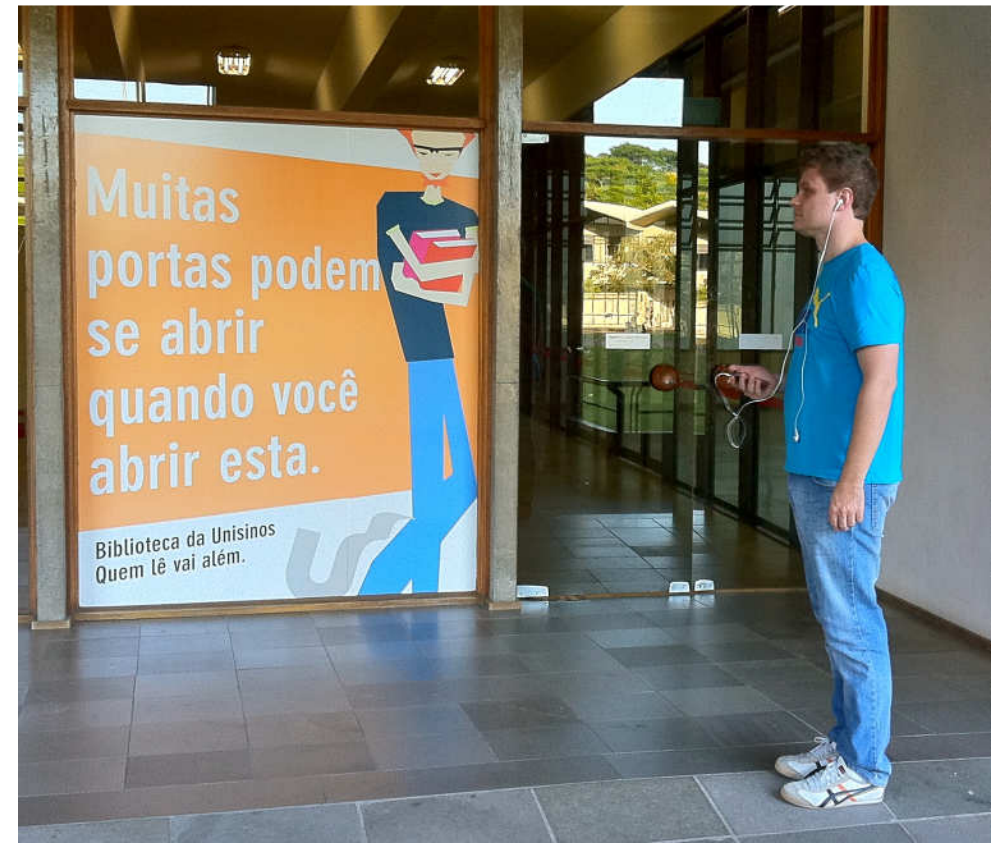

c) Teste do pedido de ajuda

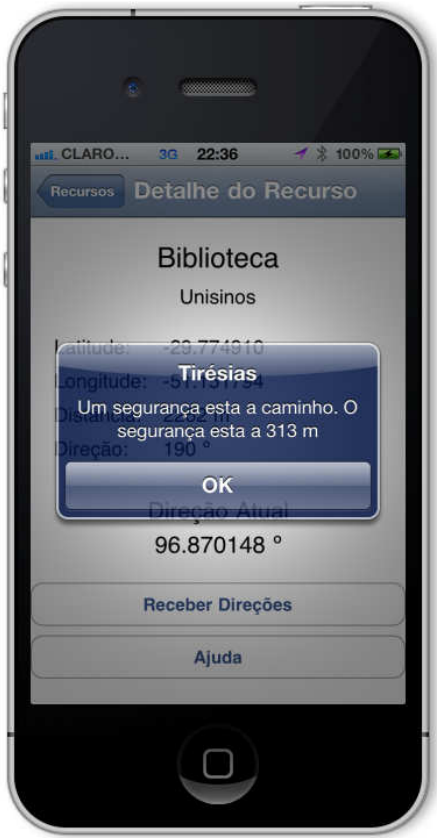

d) Captura de tela durante o teste do pedido de ajuda

Figura 8: Execução do segundo cenário

A Tabela 3 mostra a dinâmica do segundo cenário.

Tabela 3. Dinâmica do segundo cenário

\begin{tabular}{|c|c|}
\hline Ator & Ação \\
\hline Usuário & $\begin{array}{l}\text { Navega na lista de recursos e seleciona 'Centro Administrativo'. Na tela de detalhes do recurso } \\
\text { seleciona 'Receber Direções'. }\end{array}$ \\
\hline Tirésias App & $\begin{array}{l}\text { Envia ao Hefestos a localização atual do usuário e solicita um caminho para o recurso } \\
\text { selecionado. Após receber a lista de trechos, inicia a leitura do primeiro trecho. }\end{array}$ \\
\hline Usuário & $\begin{array}{l}\text { Segue as indicações referentes aos trechos lidos até chegar ao recurso solicitado, ou seja, o } \\
\text { Centro Administrativo. }\end{array}$ \\
\hline Usuário & $\begin{array}{l}\text { Novamente navega na lista de recursos, seleciona 'Biblioteca', e após seleciona 'Receber } \\
\text { Direções'. }\end{array}$ \\
\hline Tirésias App & $\begin{array}{l}\text { Envia ao Hefestos a localização do usuário e solicita um caminho para o novo recurso } \\
\text { selecionado, ou seja, o recurso 'Biblioteca'. Após receber a lista de trechos, inicia a leitura do } \\
\text { primeiro trecho. }\end{array}$ \\
\hline Usuário & Segue as indicações referentes aos trechos lidos até chegar a biblioteca. \\
\hline Usuário & $\begin{array}{l}\text { Executa o clique triplo para voltar à tela de detalhes do recurso. Na tela de detalhes seleciona a } \\
\text { opção 'Ajuda'. }\end{array}$ \\
\hline Tirésias App & $\begin{array}{l}\text { Envia ao Hefestos a localização do usuário e solicita ajuda. O Hefestos responde que um } \\
\text { funcionário foi encontrado e informa a distância dele para o usuário. }\end{array}$ \\
\hline
\end{tabular}

\subsection{Considerações sobre os cenários}

Durante a execução dos cenários, a comunicação do Tirésias com o servidor Hefestos foi realizada através da rede de dados $3 \mathrm{G}$, buscando uma condição real de uso. A rede $3 \mathrm{G}$ tende a ser mais lenta que a rede wireless disponível na universidade. Não foram detectados problemas de comunicação durante a execução dos cenários.

Além disso, o tempo de resposta do sistema mostrou-se adequado. O sistema de ajuda foi parcialmente testado, pois a localização e a notificação do funcionário foram simuladas. 
Durante a execução dos cenários, as leituras de tela foram realizadas de forma correta. Os alertas vibratórios funcionaram de forma adequada e os gestos na tela para navegação e os cliques para seleção apresentaram a funcionalidade prevista.

\section{Trabalhos relacionados}

O projeto V-Braille [30] propõe uma forma de representação de caracteres em Braile, utilizando smartphones com tela sensível ao toque em conjunto com alertas vibratórios. A tela do aparelho é dividida em seis partes, na forma de uma matriz com duas colunas e três linhas, representando os seis pontos em um caractere em Braile. Os caracteres são representados através da vibração do aparelho, onde um ponto é representado por uma vibração forte, enquanto um espaço, ou ausência de ponto, é representado por uma vibração fraca. Para cada zona da tela tocada, o aparelho vibra indicando se naquela posição da matriz figura um ponto ou um espaço. Após tocar as seis áreas o usuário percebe um caractere em braile.

Sánchez e Torre [23] desenvolveram um software para navegação autônoma usando GPS em que as informações referentes ao caminho são lidas para o usuário. Assim, o usuário é capaz de chegar a um destino específico, sem a necessidade de informações prévias sobre o ambiente. Após selecionar o destino, o sistema inicia a leitura dos trechos que compõem o caminho. O smartphone informa a direção que o usuário deve seguir através do conceito de ponteiros do relógio, o qual indica as direções de deslocamento usando a analogia com um relógio.

O projeto Trinetra [20] auxilia as pessoas com deficiência visual em suas compras no dia a dia. O Trinetra sugere uma solução para a identificação de produtos em mercados e a identificação de cédulas de dinheiro, permitindo, por exemplo, a confirmação do troco após a realização do pagamento. O projeto utiliza a tecnologia RFID para localizar e identificar os produtos. Os produtos são mapeados com uma etiqueta RFID, contendo sua identificação. Através de um leitor RFID, conectado por bluetooth ao smartphone, o sistema identifica o produto e informa ao usuário através da leitura da informação. A identificação das cédulas de dinheiro ocorre através de uma foto da cédula, obtida pelo usuário. A foto é enviada para um servidor que identifica o seu valor. Após a identificação, a informação é enviada ao smartphone, que novamente lê o resultado para o usuário.

PocketNavigator [31] propõe a utilização de diferentes padrões de vibração do aparelho, a fim de informar um caminho a ser seguido. Assim, o usuário pode deixar o aparelho no bolso, eliminado a necessidade de interação constante com ele. O sistema é baseado em dois pulsos vibratórios, onde o primeiro pulso curto indica que o usuário deve virar para a direita. De forma oposta, o primeiro pulso longo indica que o usuário deve virar à esquerda. A duração do segundo pulso indica o quanto o usuário deve se virar para a direção indicada. Três pulsos curtos indicam que o usuário deve se virar para trás.

Os seguintes critérios foram selecionados para uma comparação entre os trabalhos relacionados: (1) Configuração - indica a abrangência da solução em termos de possibilidade de configuração e/ou customização da funcionalidade que está sendo proposta; (2) Hardware específico - esse critério considera a necessidade ou não de hardware específico para a implementação da solução; (3) Completude - avalia se a proposta abrange apenas uma funcionalidade específica ou um conjunto de funcionalidades integradas, focando em uma solução; (4) Integração - esse critério avalia se a solução permite integração com outras soluções existentes, possibilitando assim a extensão de suas funcionalidades, ou mesmo a sua inclusão em outros projetos.

Considerando-se o primeiro critério, os projetos avaliados não permitem nenhum tipo de configuração, seja da funcionalidade proposta (definição da velocidade de leitura, por exemplo), seja da forma de utilização do aparelho (definições ou customizações referentes à forma de interação com a aplicação, por exemplo).

No caso do segundo critério conclui-se que os trabalhos avaliados, com exceção do Trinetra, não fazem uso de hardware específico. Trinetra sugere a utilização de dispositivos RFID para mapeamento e identificação de produtos.

Dentre os trabalhos, apenas o Trinetra apresenta uma solução completa a um determinado problema enfrentado pelas pessoas com deficiência visual. A solução proposta cobre todos os passos da interação, abordando aspectos de entrada de dados e saída dos resultados.

Em contrapartida, a solução V-Braille sugere uma forma de leitura em braile utilizando dispositivos com tela sensível ao toque, mas não especifica como os textos que serão lidos devem ser carregados na aplicação.

Finalmente, o V-Braille e o PocketNavigator apresentam explicitamente a preocupação relacionada à possibilidade de integração da solução com outras tecnologias ou soluções. Este pode ser considerado um ponto 
crítico nas soluções envolvendo acessibilidade, visto que uma fácil integração facilita a adoção da solução proposta por outros projetos.

A Tabela 4 resume a avaliação de trabalhos relacionados, incluindo modelo proposto. O Tirésias permite a configuração das suas funcionalidades, considerando esse aspecto crítico para a qualidade do sistema assistivo. $\mathrm{O}$ modelo não considera um hardware específico, inclusive sendo projetado para smartphones que tenham ou não teclado. Além disso, o Tirésias busca ser uma proposta completa para acessibilidade ubíqua a PCDV, integrando diversas soluções em um único modelo. O Tirésias também busca simplificar a integração, usando um agente assistente pessoal para intermediação da interação com outras propostas, como ocorreu com o Hefestos.

Tabela 4. Comparação entre os trabalhos relacionados

\begin{tabular}{|l|c|c|c|c|}
\hline \multicolumn{1}{|c|}{ Proposta } & Configuração & Hardware específico & Completude & Integração \\
\hline V-Braille [30] & Não & Não & Não & Não \\
\hline Navegação autônoma [23] & Não & Não & Não & Sim \\
\hline Trinetra [20] & Não & Sim & Sim & Sim \\
\hline PocketNavigator [31] & Não & Não & Não & Não \\
\hline Tirésias & Sim & Não & Sim & Sim \\
\hline
\end{tabular}

\section{Conclusão}

Este artigo propôs um modelo para acessibilidade ubíqua, orientado ao suporte de pessoas com deficiência visual. O Tirésias estende as PCDV os benefícios propostos pelo Hefestos [15], o qual suporta diversos padrões de acessibilidade [13]. Além disso, no contexto do Tirésias está sendo proposta a aplicação do UniWay [18] na definição de caminhos para recursos de acessibilidade.

No caso deste artigo, os caminhos foram orientados a PCDV, mas, no futuro, o mesmo conceito será orientado para outras deficiências. Por exemplo, cadeirantes usando cadeiras motorizadas poderão ser automaticamente guiados pelo Hefestos para chegarem a um destino específico, proporcionando assim um "piloto automático".

O modelo proposto neste trabalho foi avaliado através de cenários em um ambiente universitário. No entanto, o modelo é flexível o bastante para aplicação em outras situações, desde que seja possível a comunicação com os satélites para suporte ao GPS. Além disso, a avaliação apresentada ficou limitada a funcionalidades do Tirésias. Torna-se indispensável no futuro uma avaliação de usabilidade envolvendo usuários que possuam deficiência visual.

Finalmente, espera-se no futuro a exploração de funcionalidades adicionais, principalmente o uso de comandos de voz. O reconhecimento de voz foi considerado durante o desenvolvimento do Tirésias, inclusive com o teste de opções como o OpenEars [28]. No entanto, os resultados alcançados em avaliações iniciais não foram satisfatórios, fazendo com que o usuário tivesse que repetir várias vezes a mesma palavra.

Outra funcionalidade que poderá ser abordada em trabalhos futuros é a inclusão de suporte aos dispositivos de saída em braile. Pessoas com deficiência visual tendem a preferir o uso de dispositivos de saída em braile em comparação ao leitor de tela [30]. Esses dispositivos representam uma opção para disponibilizar as informações, principalmente em locais onde a leitura de tela não é uma opção viável, por exemplo, locais com ruído acentuado.

Finalmente, pode-se destacar que o Tirésias usa funcionalidades disponíveis na maioria dos smartphones comumente encontrados no mercado. Portanto, o seu uso não acarreta custos significativos, o que estimula a sua adoção.

\section{Agradecimentos}

Agradecemos à Fundação de Amparo à Pesquisa do Estado do Rio Grande do Sul (FAPERGS) por financiar o projeto de pesquisa "Hefestos: um modelo para suporte à acessibilidade ubíqua - Edital PqG 06/2010 - n. 1015181". 


\section{Referências}

[1] WEISER, M. The computer for the $21^{\text {st }}$ century. Scientifc American, v. 265, no 3. 1991. p. 94-104.

[2] SATYANARAYANAN, M. 2001. Pervasive computing: vision and challenges. IEEE Personal Communications. v.8, 4 (Aug. 2001), 10-17. Disponível em: http://dx.doi.org/10.1109/98.943998.

[3] HIGHTOWER, J., AND BORRIELLO, G. Location Systems for Ubiquitous Computing. IEEE Journal, v. 34, 8 (Aug. 2001), 57-66. 2001. Disponível em: http://dx.doi.org/10.1109/2.940014.

[4] J. HIGHTOWER, A.J. LAMARCA, AND SMITH, I. "Practical Lessons from Place Lab", IEEE Pervasive Computing, v. 5, no. 3, 2006, pp.32-39. Disponível em: http://dx.doi.org/10.1109/MPRV.2006.55.

[5] DEY, A., HIGHTOWER, J., LARA, E. AND DAVIES, N. 'Location-based services', IEEE Pervasive Computing, v. 9, no. 1, pp.11-12, 2010. Disponível em: http://dx.doi.org/10.1109/MPRV.2010.10.

[6] VAUGHAN-NICHOLS, S. Will Mobile Computing's Future Be Location, Location, Location? Journal Computer, IEEE Press, v.42, 2 (Feb. 2009), 14-17, 2009. Disponível em: http://dx.doi.org/10.1109/MC.2009.65.

[7] BALDAUF, M., AND DUDSTAR, S. A Survey on Context-aware Systems. International Journal of Ad Hoc and Ubiquitous Computing. v.2, 4, 263-277, 2007. Disponível em: http://dx.doi.org/10.1504/IJAHUC.2007.014070.

[8] DEY, A. K. Understanding and Using Context. Journal Personal and Ubiquitous Computing. v.5, 1 (Feb. 2001), 4-7, 2001. Disponível em: http://dx.doi.org/10.1007/s007790170019.

[9] BARBOSA, J., HAHN, R., BARBOSA, D., AND SACCOL A. A Ubiquitous Learning Model Focused on Learner Integration. International Journal of Learning Technology. v.6, 1, 62-83, 2011. Disponível em: http://dx.doi.org/10.1504/IJLT.2011.040150.

[10]FRANCO, L., ROSA, J., BARBOSA, J., COSTA, C., AND YAMIN, A. MUCS : A Model for Ubiquitous Commerce Support. Eletronic Commerce Research and Applications. v.1, 1-38, 2010. Disponível em: http://dx.doi.org/10.1016/j.elerap.2010.08.006.

[11]SEGATTO, W., HERZER, E., MAZZOTTI, C.L., BITTENCOURT, J.R. AND BARBOSA, J.L.V. moBIO threat: a mobile game based on the integration of wireless technologies, ACM Computers in Entertainment, v. 6 , no. 3, pp.1-14, 2008.

[12] BRAZILIAN INSTITUTE OF GEOGRAPHY AND STATISTICS. Census 2010. Last Acessed April 2012. Disponível em: http://www.ibge.gov.br/home/estatistica/populacao/censo2010/sinopse.pdf.

[13]PUPO, D., MELO, A., AND FERRÉS, S. Accessibility: discourse and practice in everyday of libraries. ISBN: 85-85783-16-8, 2006. UNICAMP/ Cesar Lattes Central Library.

[14] VANDERHEIDEN, G. Ubiquitous accessibility, common technology core, and micro assistive technology. ACM Transactions on Accessible Computing (TACCESS). v. 1, 2, Article 10, 2008. Disponível em: http://dx.doi.org/10.1145/1408760.1408764.

[15] TAVARES, J., BARBOSA, J., COSTA, C., YAMIN, A., AND REAL, R. Computação Ubíqua Aplicada à Acessibilidade. In: XVII Simpósio Brasileiro de Sistemas Multimídia e Web (WebMedia). Florianópolis, 252-259, 2011.

[16] ABASCAL, J., CASAS, R., MARCO, A., SEVILLANO, J., AND CASCADO, D. Towards an intelligent and supportive environment for people with physical or cognitive restrictions. In Proceedings of the $2^{\text {nd }}$ International Conference on Pervasive Technologies Related to Assistive Environments (Corfu, Greece, June 9-13). PETRA'09. ACM, New York, NY, Article 10, 2009. Disponível em: http://dx.doi.org/10.1145/1579114.1579124.

[17] METSIS, V., LE, Z., LEI, Y., AND MAKEDON, F. Towards an Evaluation Framework for Assistive Environments. In Proceedings of the 1st International Conference on Pervasive Technologies Related to 
Assistive Environments (Athens, Greece, July 15-19). PETRA'08. ACM, New York, NY, Article 12, 2008. Disponível em: http://dx.doi.org/10.1145/1389586.1389601.

[18]CAMPES, C. AND BARBOSA, J. Uniway - Um sistema de localização e descoberta do menor caminho para a Universidade do vale do Rio dos Sinos (UNISINOS). Relatório do Programa Institucional de Bolsas de Desenvolvimento Tecnológico e Inovação do CNPq - PIBITI/CNPq/Unisinos, São Leopoldo, 2011.

[19]DIJKSTRA, E. A Note on Two Problems in Connexion with Graphs. Numerische Mathematik, v. 1, 1959.

[20]NARASIMHAN, P., GANDHI, R. AND ROSSI, D. Smarphone-Based Assistive Technologies for the Blind. CASES'09, Grenoble, 2009. Disponível em: http://dx.doi.org/10.1145/1629395.1629427.

[21] KANE, S., JAYANT, C., WOBBROCK, J. AND LADNER, R. Freedom to Roam: A Study of Mobile Device Adoption and Accessibility for People with Visual and Motor Disabilities. Seattle: [s.n.], 2009. Disponível em: http://dx.doi.org/10.1145/1639642.1639663.

[22] AZENKOT, S. AND FORTUNA, E. Improving Public Transit Usability for Blind and Deaf-Blind People by Connecting a Braille Display to a Smartphone. Orlando: [s.n.], 2010. Disponível em: http://dx.doi.org/10.1145/1878803.1878890.

[23] SÁNCHEZ, J. AND TORRE, N. Autonomous Navigation through the city for the blind. ASSETS'10, Orlando, 2010. Disponível em: http://dx.doi.org/10.1145/1878803.1878838.

[24] GUERREIRO, T., LAGOÁ, P., NICOLAU, H., SANTANA, P. AND JORGE, J. Mobile Text-Entry Models for People with Disabilities. ECCE'08, Madeira, 2008. Disponível em: http://dx.doi.org/10.1145/1473018.1473067.

[25]LAGOÁ, P., SANTANA, P., GUERREIRO, T., GONÇALVES, D. AND JORGE, J. BloNo: A New Mobile Text-Entry Interface for the Visually Impared. Universal Access in HCI, Lisboa, 2007. Disponível em: http://dx.doi.org/10.1007/978-3-540-73281-5_99.

[26] HAILPERN, J., REID, L., BARDMAN, R. AND ANNAM, S. WEB 2.0: Blind to an Accessible New World. WWW'09, Madri, 2009. Disponível em: http://dx.doi.org/10.1145/1526709.1526820.

[27] PADGHAM, L. AND WINIKOFF, M. Prometheus: A Methodology for Developing Intelligent Agents. Melbourne: [s.n.], 2002.

[28] POLITEPIX. OpenEars: a library for voice recognition for iPhone. Politepix: Where the pixels are polite, now with iPhone app development. Disponível em: http://www.politepix.com/openears. Acesso em: set. 2012.

[29]DEY, A., SALBER, D., AND ABOWD G. 2001. A conceptual framework and a toolkit for supporting the rapid prototyping of context-aware application. Journal Human-Computer Interaction. v.16, 2, 97-166, 2001. Disponível em: http://dx.doi.org/10.1207/S15327051HCI16234_02.

[30] JAYABT, C., ACUARIO, C., JOHNSON, W., HOLLIER, J. AND LADNER, R. VBraille: Haptic Braille Perception Using a Touch-screen and Vibration on Mobile Phones. ASSETS'10, Orlando, USA, 2010. Disponível em: http://dx.doi.org/10.1145/1878803.1878878.

[31] PIELOT, M., POPPINGA, B. AND BOLL, S. PocketNavigator: Vibro-Tactile Waypoint Navigation for Everyday Mobile Devices. MobileHCI'10, Lisboa, Portugal, 2010. Disponível em: http://dx.doi.org/10.1145/1851600.1851696. 